\title{
Pushing the limits - Low level Ca isotopic analysis using DS MC TIMS in biological tissues
}

\author{
ANIKA RETZMANN ${ }^{1}$, DOROTHY WALLS ${ }^{2}$, KERRI A. \\ MILLER $^{2}$, JOHANNA IRRGEHER $^{1,2}$, THOMAS PROHASKA $^{1,2^{*}}$, \\ MICHAEL WIESER ${ }^{2}$ \\ ${ }^{1}$ Chair of General and Analytical Chemistry, \\ Montanuniversität Leoben, Austria. (*correspondence: \\ thomas.prohaska@unileoben.ac.at) \\ ${ }^{2}$ Department of Physics and Astronomy, University of \\ Calgary, Canada.
}

Introduction: Previous studies have shown that biological processes like biomineralization and (human) $\mathrm{Ca}$ homeostasis can result in a significant fractionation of $\mathrm{Ca}$ isotopes. Therefore, the analysis of $\mathrm{Ca}$ isotope ratios in human blood and urine has great potential as diagnostic tool for monitoring changes in bone mineral balance and identifying bone diseases like osteoporosis. The extent of natural variations of stable $\mathrm{Ca}$ isotopes is small, with a variation of about $4 \% 0-5 \%$ in the $\delta\left({ }^{44} \mathrm{Ca} /{ }^{40} \mathrm{Ca}\right)$ ratio. Therefore reliable measurement of calcium isotopic composition has remained very challenging, especially considering low $\mathrm{Ca}$ levels and significant procedural blank levels. The number and large mass dispersion of stable $\mathrm{Ca}$ isotopes $(40,42,43,44,46,48)$, instrumental isotopic fractionation, isobaric interferences and blank contribution are the major analytical challenges - all influencing the uncertainty of the method.

Method: In this study, Ca purification was performed using the DGA resin, optimized for low procedural blanks and matrix separation from $\mathrm{K}, \mathrm{Mg}$, $\mathrm{Ti}$ and $\mathrm{Fe} . \mathrm{A}{ }^{42} \mathrm{Ca}-{ }^{48} \mathrm{Ca}$ double spike (DS) was applied to correct for potential isotopic fractionation during $\mathrm{Ca}$ purification and measurement. Ca isotope analysis was performed using a thermal ionization mass spectrometer (TIMS), operated in dynamic mode with two lines. Data reduction of the measured $\mathrm{Ca}$ isotope ratios was performed using in-house developed software solving the DS algorithm.

Results: The developed DS TIMS method enabled processing of total $\mathrm{Ca}$ amounts of $1000 \mathrm{ng}$, with a total procedural blank of $<10 \mathrm{ng}$. The the measured $\delta\left({ }^{44} \mathrm{Ca} /{ }^{40} \mathrm{Ca}\right)_{\text {NIST }}$ SRM915a values of separated NIST SRM 915a was found to be $0.01 \% \circ \pm 0.13 \%$ o $(2 S D, n=30)$ and the values of the reference material NIST SRM 1400 (bone ash, NIST SRM 1486 (bone meal) and IAPSO (seawater) were within uncertainty in good agreement with literature data. Novel data on additional reference materials for biological tissues (blood, bovine liver, hair) will be presented. 